\title{
Adult onset of multisystem Langerhans cell histiocytosis with skin and lymph node involvement
}

\author{
Izabela Błażewicz ${ }^{1}$, Wojciech Biernat ${ }^{2}$, Anna Kowalczyk ${ }^{3}$, Wioletta Barańska-Rybak ${ }^{1}$, Roman Nowicki ${ }^{1}$, \\ Marta Stawczyk-Macieja' ${ }^{1}$, Małgorzata Sokołowska-Wojdyło ${ }^{1}$
}

\author{
1Department of Dermatology, Venereology and Allergology, Medical University of Gdansk, Gdansk, Poland \\ Head of the Department: Prof. Roman Nowicki MD, PhD \\ ${ }^{2}$ Department of Pathology, Medical University of Gdansk, Gdansk, Poland \\ Head of the Department: Prof. Wojciech Biernat MD, PhD \\ ${ }^{3}$ Department of Oncology and Radiotherapy, Medical University of Gdansk, Gdansk, Poland \\ Head of the Department: Prof. Wojciech Biernat MD, PhD
}

Postep Derm Alergol 2015; XXXII (3): 225-228

DOI: $10.5114 /$ pdia.2014.40970

Langerhans cell histiocytosis (LCH) is a rare disorder characterized by clonal proliferation of dendritic cells, which comprises a wide range of clinical presentations. The term LCH is used to include a spectrum of disorders previously termed: histiocytosis $X$, eosinophilic granuloma, Hand-Schüller-Christian disease, Letterer-Siwe disease and Hashimoto-Pritzker disease. The etiology of the lesion is still elusive, and the question of whether LCH is a reactive or neoplastic disorder remains unanswered [1]. The LCH mainly affects children under 10 years of age, but can occur at any age. The estimated incidence in adults is about 1-2 cases per million and is lower than that in children [2]. The LCH may affect any organ, but the most common locations include bone [3-6], mucous membranes [7], skin [8], lymph nodes, lung [9], pituitary [10] and liver [11]. The clinical course and prognosis of $\mathrm{LCH}$ is diverse ranging from a spontaneously regressing single lesion to a life-threatening multisystem disease with rapid progression and death. This disorder may involve single or multiple organs and has an unpredictable course. Diagnosis of LCH is difficult and may be delayed due to its rarity and wide clinical manifestation.

A 41-year-old woman was admitted to the Department of Dermatology, Venereology and Allergology in Gdansk due to diffuse erythematous-edematous skin lesions and numerous nodules localized on the face (Figure 1). The physical examination revealed also $2 \times 2 \mathrm{~cm}$ sized ulcer covered with necrotic tissue on the skin of the left lower extremity and generalized lymphadenopathy. The lesions have been present for 2 years and were initially diagnosed as rosacea. Because of suspicion of discoid lupus erythematosus the patient was also treated with chloroquine phosphate, with no improvement. The histopathological and immunohistochemical examination of the skin did not confirm the diagnosis. During the hospitalization in the Department of Dermatology, the diagnostic tests (magnetic resonance imaging (MRI) of the craniofacial area, computed tomography (CT) of the chest, bone marrow biopsy, chest X-ray, immunophenotypic examination of peripheral blood, ultrasonography of lymph nodes) were performed, but they did not reveal any abnormalities. On the basis of histopathological examination of the skin, mycosis fungoides was initially diagnosed. Treatment with methotrexate at the dose of $25 \mathrm{mg}$ per week (4 courses) was ineffective (Figure 2). Cervical lymph node biopsy was performed and on the basis of histopathological examination, Langerhans cell histiocytosis was diagnosed (Figure $3 \mathrm{~A}$ ). The neoplastic cells showed the following phenotype: CD1a+, S100-, CD2-, CD3-, CD68-, CD56-, thiaphorin-1-, CD21-, Granzyme B-, CD5- (Figure 3 B). The final diagnosis of LCH was based on the clinical picture, histopathological examination of the lymph node and re-examination of the skin biopsy. Diagnosis of LCH was confirmed by immunohistochemical staining, which revealed the presence of aggregates of CD1a+ cells. Prednisone therapy at the initial dose of $1 \mathrm{mg} / \mathrm{kg} /$ day was started. During the treatment rapidly growing facial edema occurred, resulting from compression by enlarged carotid lymph nodes on the blood vessels (Figure 4). In the Department of Oncology and Radiotherapy in Gdansk, the chemotherapy with cladribine was initiated ( $5 \mathrm{mg} / \mathrm{m}^{2} /$ day for 5 days every $4-6$ weeks). The patient was given 6 courses of chemotherapy with a significant improvement (Figure 5). Unfortunately,

Address for correspondence: Izabela Błażewicz, Department of Dermatology, Venereology and Allergology, Medical University of Gdansk, 7 Debinki St, 80-952 Gdansk, phone: +48 791002 315, e-mail: izabela.blazewicz@wp.pl Received: 14.11.2013, accepted: 6.01.2014. 

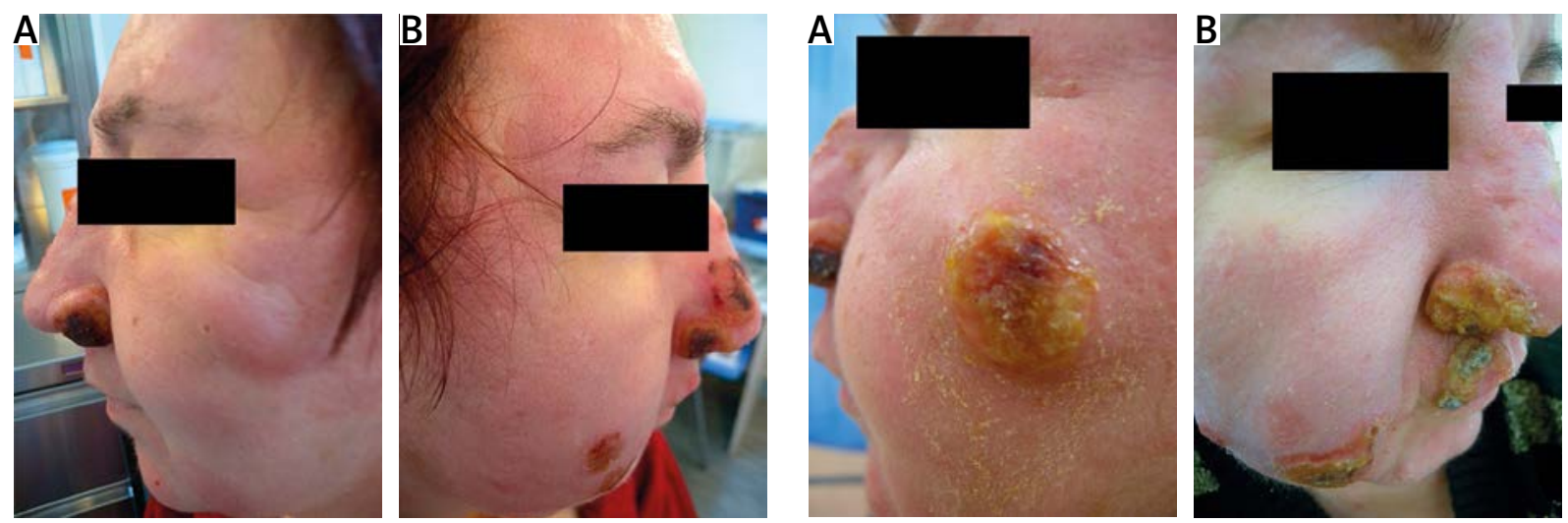

Figure 1 A, B. Clinical appearance before treatment

Figure 2 A, B. Clinical appearance after four courses of methotrexate
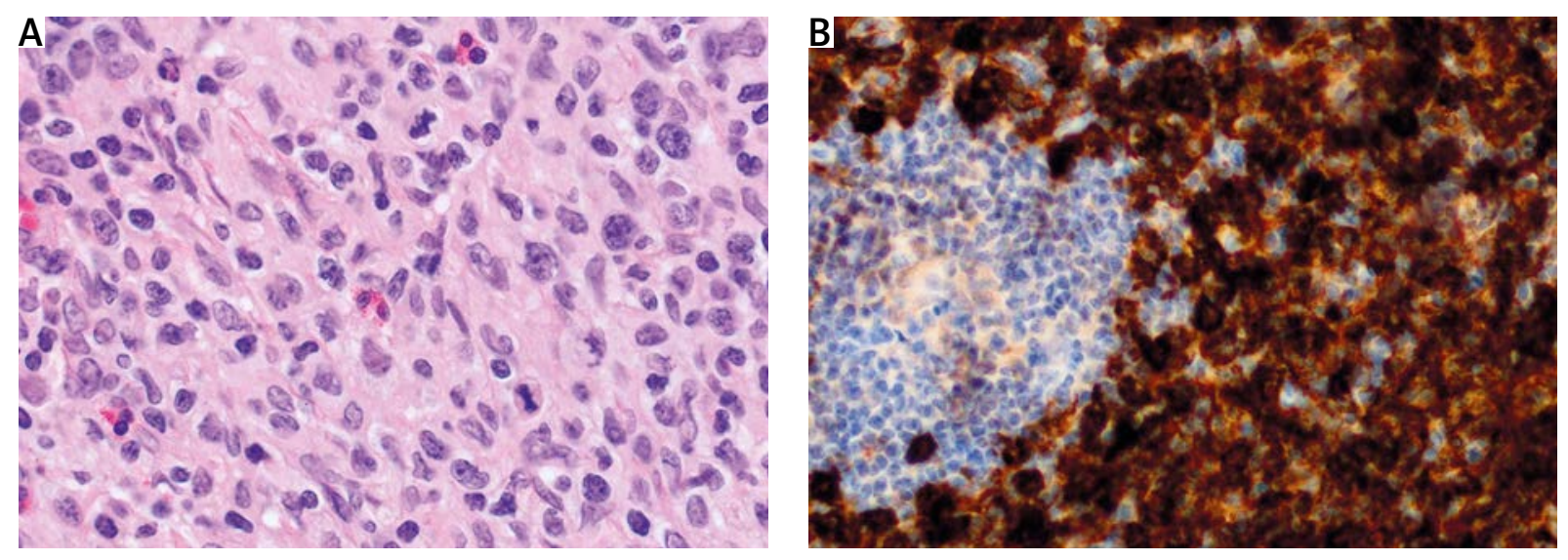

Figure 3. A - Lymph node involvement by neoplastic Langerhans cells. B - Predominant location of tumour cells in the perifollicular area demonstrated by the expression of antigen CD1a

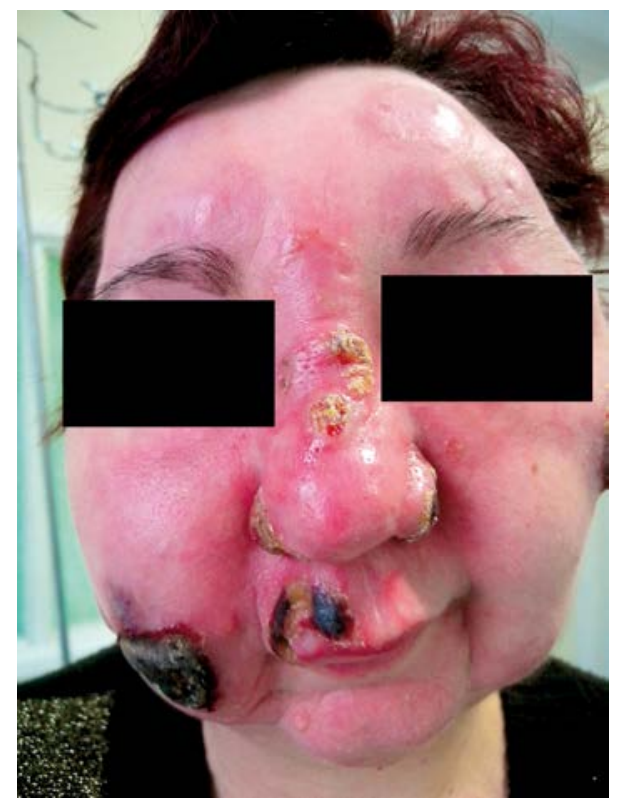

Figure 4. Progression of changes during treatment with prednisone (the photograph shows the real state)
2 months after completion of treatment, papular lesions localized on the trunk occurred (Figure 6). The histopathological examination of them revealed LCH (Figure 7). The patient was referred to the Department of Oncology and Radiotherapy in Gdansk. The chemotherapy with vinblastine and prednisone is taken into consideration.

The histiocytoses encompass a wide range of conditions that may be primary or secondary, limited or multiple, benign or malignant. On the basis of the clinical picture, LCH can be divided into a single system LCH (SS$\mathrm{LCH}$ ), in which one of the organs is affected and multisystem LCH (MS-LCH) involving at least two organs. The MS-LCH is subdivided into 'low-risk' and 'high-risk' ones. Low-risk patients have no involvement of 'high-risk' organs (liver, lungs, spleen, hematopoietic cells). High-risk patients have one or more of these organs involved [12]. We diagnosed multisystem LCH in our patient, because both skin and lymph nodes were affected. Skin lesions are a common manifestation of LCH. They are usually the first symptom of the disease, being reported in $80 \%$ of cases. Cutaneous lesions have been described as scaly, erythematous, seborrhea-like eruptions of brown to red 

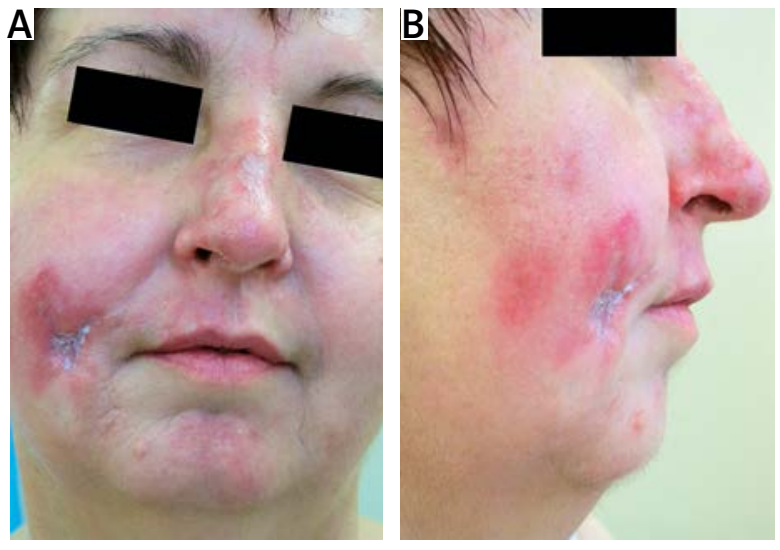

Figure 5 A, B. Clinical appearance after two courses of chemotherapy with cladribine

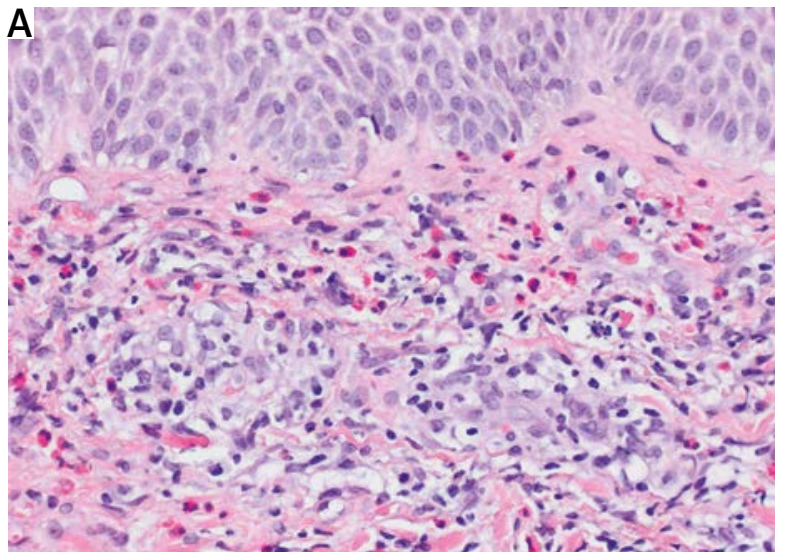

Figure 7. A - Skin biopsy showing subepidermal aggregates of large clear cells in the perivascular location disclosing CD1a expression. B - Note the lack of epidermal involvement by tumour cells and accompanying eosinophils. CD1a positivity in the epidermis reveals native dendritic Langerhans cells

papules. The most frequently involved sites include the face, scalp and trunk $[13,14]$.

According to the criteria established by the International Histiocyte Society, the diagnosis of LCH is based on the histological and immunophenotypic examination of lesional tissue. The main feature is the morphologic identification of the characteristic LCH cells. Additionally, positive staining of the lesional cells with CD1a and/or langerin (CD207) is required for definitive diagnosis [12]. In our case, the final diagnosis was based on the clinical picture, histopathological examination of the lymph node and re-examination of the skin biopsy. Diagnosis was confirmed by immunohistochemical staining, which revealed the presence of CD1a+ cells. The differential diagnosis included mainly Rosai-Dorfman disease, characterized by generalized, massive lymphadenopathy, and the presence of systemic symptoms. Based on the histopathological examination of the lymph node and immunohistochemical staining we excluded Rosai-Dorfman disease, which presents no expressionof CD1a marker.
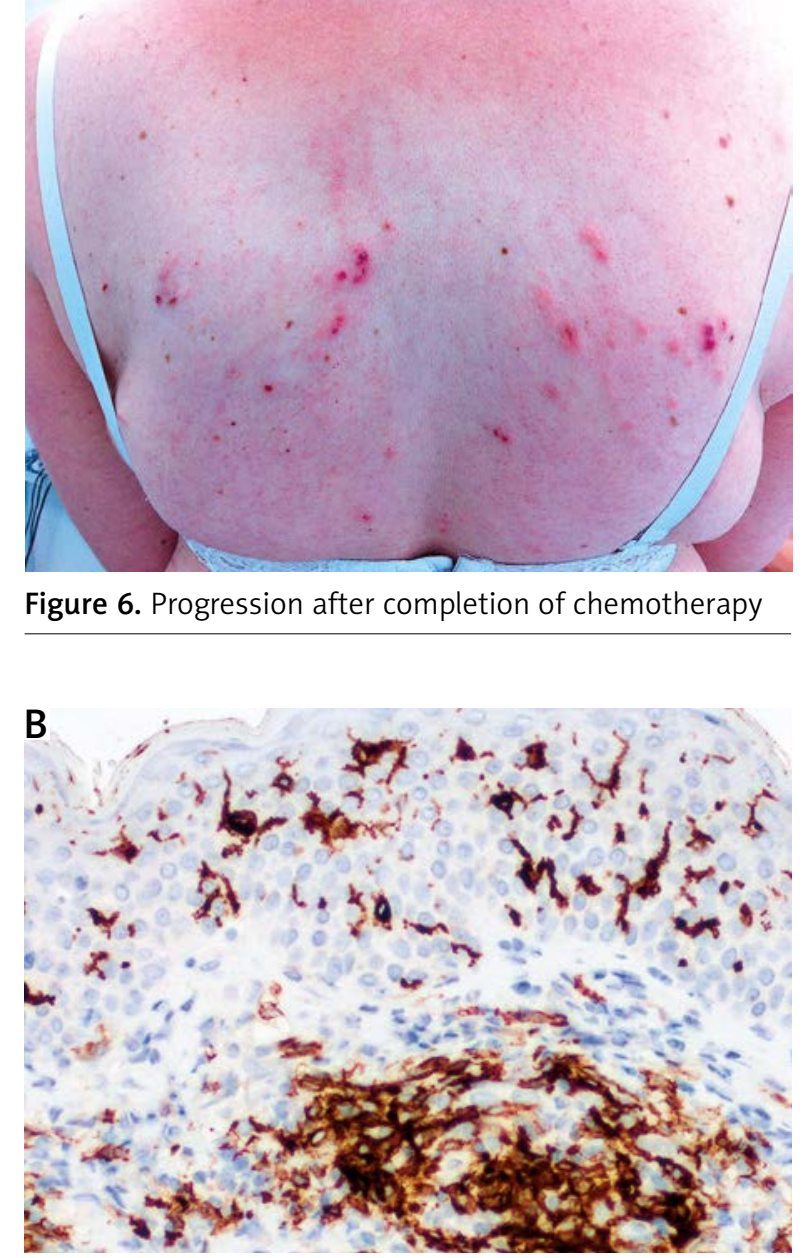

Figure 6. Progression after completion of chemotherapy of onset, number of organs involved, organ dysfunction, and severity of disease $[15,16]$.

International guidelines for the diagnosis and treatment of adult patients with LCH are not available. Most of the reports are connected with pediatric studies. Local or systemic corticosteroids, PUVA and narrow band ultraviolet $B$, thalidomide, azathioprine, methotrexate are possible therapeutic options in mild forms of cutaneous $\mathrm{LCH}$, while more severe forms may need chemotherapy. Systemic therapy should be considered in MS-LCH and SS-LCH with multifocal lesions. There is no first-line therapy in adult $\mathrm{LCH}$. According to the guidelines of the Histiocyte Society a combination of prednisone and vinblastine has been proven to be effective treatment with minimal toxicity and is therefore the standard initial therapy for all patients with MS-LCH [12]. The abovementioned combination has never been proven effective for adults in a prospective study [13]. According to the first international study for LCH in adults performed 
by the Histiocyte Society in 2004, patients with MS-LCH should receive vinblastine and prednisone combination for 6 weeks followed by continuation treatment with 6-mercaptopurine, prednisone and vinblastine for 6 to 12 months. According to literature reports and high response rates ranging from $64 \%$ to $100 \%$, we decided to initiate therapy with cladribine [17-19]. Unfortunately, 2 months after completion of chemotherapy we observed progression. The poor response in our case may be connected with the delay in final diagnosis and treatment.

Further therapy depends on the patient response to initial therapy. Currently, there is insufficient evidence about the optimal course of treatment for patients with severe progressive MS-LCH who do not respond to standard therapy [13]. Chemotherapy agents such as vinblastine, methotrexate, etoposide and cyclophosphamide have been used in those cases with diverse response $[20,21]$.

The future for LCH patients looks brighter because of the development of new treatment possibilities. There are single reports about effective treatment with thalidomide [22], clofarabine, acitretin and the monoclonal antibody anti-CD52 [23]. In cases of the aggressive form of LCH, combination chemotherapies (MACOP-B) [24] and chemotherapy followed by allogeneic blood stem cells transplantation can be effective $[25,26]$. Treatment of this condition needs to be performed in specialist centres because the management is multidisciplinary requiring care of oncologists, dermatologists and endocrinologists.

\section{Conflict of interest}

The authors declare no conflict of interest.

\section{References}

1. Abla O, Egeler RM, Weitzman S. Langerhans cell histiocytosis: current concepts and treatments. Cancer Treat Rev 2010; 36: 354-9.

2. Stockschlaeder M, Sucker C. Adult Langerhans cell histiocytosis. Eur J Haematol 2006; 76: 363-8.

3. Chai D, Tao Y, Bao Z, et al. The adverse prognostic hallmarks in identical twins with Langerhans cell histiocytosis: a clinical report and literature review. Tohoku J Exp Med 2013; 230: 219-25.

4. Erdem H, Kadıoğlu N, Uzunlar AK, et al. Langerhans cell histiocytosis mimicking osteomyelitis in an infant. APSP J Case Rep 2013; 4: 27.

5. Azreen AB, Kwan CY, Prepagaren N. Langerhans cell histiocytosis of maxillary sinus. Med J Malaysia 2012; 67: 627-8.

6. Gungadeen A, Kullar P, Yates P. Otic langerhans' cell histiocytosis in an adult: a case report and review of the literature. Case Rep Otolaryngol 2013; 2013: 259726.

7. George KT, Anand R, Ganasalingam S, et al. Multisystem Langerhans cell histiocytosis presenting as an oral lesion. J Oral Maxillofac Pathol 2013; 17: 106-9.

8. Chandekar SA, Shah VB, Kavishwar V. Cytological diagnosis of Langerhans cell histiocytosis with cutaneous involvement. J Cytol 2013; 30: 81-3.
9. de Mello RA, Tanos JW, Mello MB, et al. Multisystemic Langerhans cell histiocytosis with advanced lung involvement. J Radiol Case Rep 2012; 6: 22-8.

10. Funk RK, Ferraro DJ, Perrin RJ, et al. Recurrent adult-onset hypophyseal Langerhans cell histiocytosis after radiotherapy: a case report. J Med Case Rep 2012; 6: 341.

11. Liu DG, Zhang YX, Li F. Multisystem Langerhans cell histiocytosis with liver dysfunction as the first presentation: a case report. Oncol Lett 2012; 3: 391-4.

12. Histiocyte Society 2009. Langerhans cell histiocytosis evaluation and treatment guidelines. Histocyte Society online, 2009, cited 2010-02. Available from: http://www.histiocytesociety.org/site/c.mqISL2PIJrH/b.4442715/k.A339/Treatment_Plans.htm.

13. Girschikofsky M, Arico M, Castillo D. Management of adult patients with Langerhans cell histiocytosis: recommendations from an expert panel on behalf of Euro-Histio-Net. Orphanet J Rare Dis 2013; 8: 72.

14. Satter EK, High WA. Langerhans cell histiocytosis: a review of the current recommendations of the Histiocyte Society. Pediatr Dermatol 2008; 25: 291-5.

15. Gadner H, Grois N, Arico M, et al. A randomized trial of treatment for multisystem Langerhans cell histiocytosis. J Pediatr 2001; 138: 728-34.

16. Lahey ME. Prognostic factors in histiocytosis X. Am J Pediatr Hematol Oncol 1981; 3: 57-60.

17. Saven A, Burian C. Cladribine activity in adult Langerhanscell histiocytosis. Blood 1999; 93: 4125-30.

18. Pardanani A, Phyliky RL, Li CY, et al. Chlorodeoxyadenosine therapy for disseminated Langerhans cell histiocytosis. Mayo Clin Proc 2003; 78: 301-6.

19. Mottl H, Starý J, Chánová M, et al. Treatment of recurrent Langerhans cell histiocytosis in children with 2-chlorodeoxyadenosine. Leuk Lymphoma 2006; 47: 1881-4.

20. Gadner H, Grois N, Arico M, et al. A randomized trial of treatment for multisystem Langerhans cell histiocytosis. J Pediatr 2001; 138: 728-34.

21. Howarth DM, Gilchrist GS, Mullan BP, et al. Langerhans cell histiocytosis: diagnosis, natural history, management, and outcome. Cancer 1999; 85: 2278-90.

22. Misery L, Larbre B, Lyonnet S, et al. Remission of Langerhans cell histiocytosis with thalidomide treatment. Clin Exp Dermatol 1993; 18: 487.

23. Jordan MB, McClain KL, Yan X, et al. Anti-CD52 antibody, alemtuzumab, binds to Langerhans cells in Langerhans cell histiocytosis. Pediatr Blood Cancer 2005; 44: 251-4.

24. Gadner H. Treatment of adult-onset Langerhans cell histiocytosis - is it different from the pediatric approach? Ann Oncol 2010; 21: 1141-2.

25. Akkari V, Donadieu J, Piguet, et al. Hematopoietic stem cell transplantation in patients with severe Langerhans cell histiocytosis and hematological dysfunction: experience of the French Langerhans Cell Study Group. Bone Marrow Transplant 2003; 31: 1097-103.

26. Kinugawa N, Imashuku S, Hirota Y, et al. Hematopoietic stem cell transplantation (HSCT) for Langerhans cell histiocytosis (LCH) in Japan. Bone Marrow Transplant 1999; 24 : 935-8. 